\title{
Teleorthodontic treatment with clear aligners: An analysis of outcome in treatment supervised by general practitioners versus orthodontic specialists
}

\author{
Marc B Ackerman ${ }^{1,2 *}$ \\ ${ }^{1}$ American Teledentistry Association, Wellesley Hills, Massachusetts, USA \\ ${ }^{2}$ Department of Developmental Biology, Harvard School of Dental Medicine, Boston, Massachusetts, USA
}

\begin{abstract}
The objective of this study was to assess the clinical effectiveness of teleorthodontic treatment with clear aligners on maxillary and mandibular incisor alignment utilizing the SmileDirectClub ${ }^{\circledR}$ teleorthodontic platform, to objectively measure differences in clinical effectiveness between treatment supervised by general practitioners versus orthodontic specialists and to subjectively consider patient satisfaction after the teleorthodontic delivery of clear aligner treatment and the relationship between satisfaction and whom the treatment was provided by. A sample of 50 patients determined by inclusion and exclusion criteria were randomly selected from an initial sample of 200 patients. The pre and posttreatment maxillary and mandibular arch stereolithography (STL) files taken from the iTero digital scans were imported into computer software for measurement. Point to point millimetric measurement of crowding or spacing was measured from the distal of one maxillary or mandibular lateral incisor to the distal of the opposite lateral incisor on the pre and posttreatment models. Lastly, the subjective measure of patient satisfaction was tabulated for each patient. General linear models found treatment effectiveness to achieve statistical significance in the multivariate tests conducted. There was no statistically significant difference between treatment supervised by general practitioners versus orthodontic specialists. Lastly, Fisher's exact test determined that there was no significant association between satisfaction and who the respondent was treated by.
\end{abstract}

\section{Introduction}

Technologic advancements in the delivery of clinical orthodontic care have lowered practice overhead, shortened treatment time, and placed less of a burden on the orthodontist. Most orthodontic practices can see far more patients per day than ever before. However, in a recent survey of orthodontists no participant was "too busy" to treat all persons requesting appointments [1]. Two leading factors that have created excess capacity in the contemporary orthodontic delivery model are the high cost of treatment and the burden of a significant amount of time away from work or other activities for the patient.

Telemedicine has been employed in various forms for over two decades. Low acuity (non-serious health problem) patients have been successfully treated via telemedicine for such medical conditions as sinusitis and urinary tract infections (UTI). A study found that the fraction of patients with any follow up for sinusitis or UTIs was the same between telemedicine and in office visits [2]. This measure is a very good proxy for misdiagnosis or treatment failure. Teledentistry has also been shown to be very safe and effective for low acuity dental patients [3]. A systematic review examined the accuracy of detecting tooth decay from photographs versus direct visual inspection of the patient and found comparable results between both modalities [4]. The accuracy of direct examination versus teledental examination in the diagnosis of dental pathology in older adults in nursing homes, a higher acuity group of patients, has also been investigated. It was found that teledentistry exams had excellent diagnostic accuracy and were much quicker than face-to-face exams, 12 minutes versus 20 minutes [5]. A randomized controlled trial evaluating teledentistry for screening new patient orthodontic referrals found that teledentistry was a valid system for positively identifying appropriate new patient orthodontic referrals [6]. There is ample evidence in the scientific literature that confirms the clinical effectiveness of teledentistry and how it increases access to care for the patient [7-9].

Over 60 percent $(1,972)$ of the counties in the United States do not have an orthodontist's office [10]. The new teleorthodontic delivery model of clear aligner treatment [11] has the potential to bridge the gap in this access to care divide. Patients who for many different reasons had been previously denied access to orthodontic care, now have a viable option for addressing anterior tooth alignment issues and obtain a detectable improvement in their social smile (Figure 1). There has been a great deal of confusion about the definition of teleorthodontics which has unfortunately negatively influenced orthodontists, state dental boards, and the lay public [11]. Teleorthodontics is the delivery of health information and orthodontic care across distances using information technology and telecommunications. Teleorthodontics encompasses diagnosis, treatment, monitoring and prevention, continuing education of providers and consumers, and research. Do-it-yourself orthodontics has been used synonymously with both teleorthodontics treatment with clear aligners [12]. When in fact, do-it-

*Correspondence to: Marc B Ackerman, American Teledentistry Association, 9 Roberts Road, Wellesley Hills, MA, USA, Tel: 1-781-304-4409; E-mail: admin@americanteledentistry.org

Key words: teledentistry, teleorthodontics, orthodontic treatment, clear aligners, incisor alignment, orthodontic specialist, general practitioner

Received: May 02, 2019; Accepted: May 13, 2019; Published: May 16, 2019 

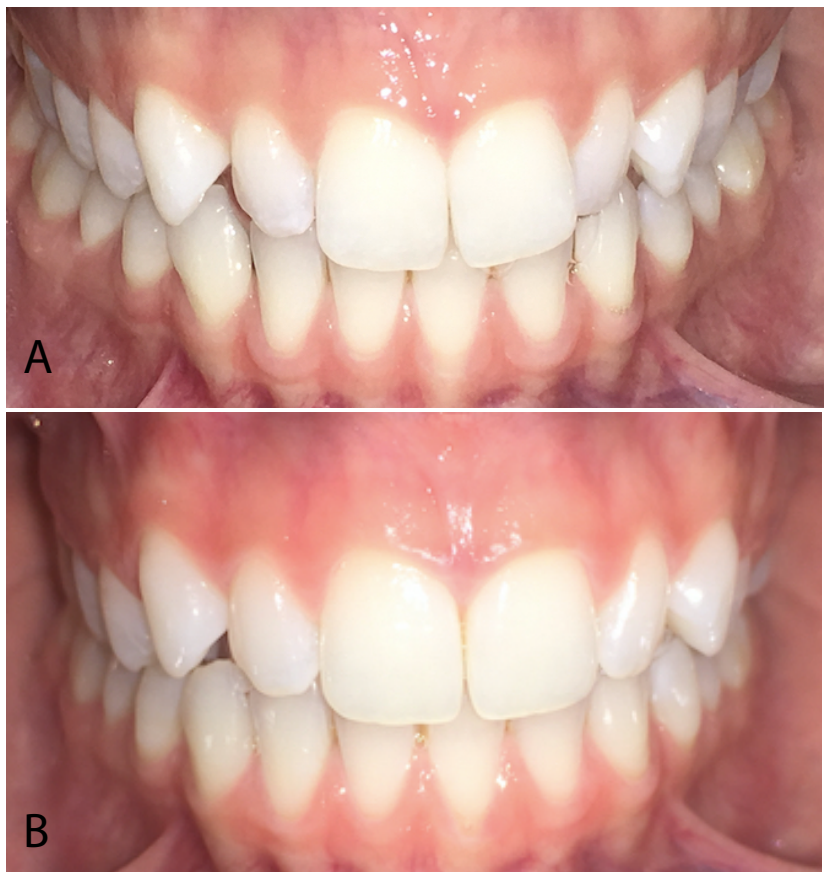

Figure 1. The average study patient who underwent doctor-directed at home clear aligner treatment. Most consumers who elect to undergo doctor-directed clear aligner treatment are seeking a detectable improvement in anterior tooth display. A. Pretreatment photograph. B. Posttreatment photograph.

yourself orthodontics refers to a patient's self-directed efforts to move teeth without the supervision of a doctor.

A recent systematic review examined the clinical effectiveness of in-office orthodontic treatment with clear aligners provided by orthodontic specialists [13]. It found that Invisalign ${ }^{\bullet}$ (Santa Clara, CA) aligners can safely straighten dental arches in terms of aligning the incisor teeth. There are several studies in the literature that have investigated $[14,15]$, the differences in approach to treatment planning and usage of the Invisalign ${ }^{\circledR}$ system between general practitioners and orthodontic specialists. However, there have been no studies assessing the clinical effectiveness of teleorthodontic treatment with clear aligners. Consequently, there are no studies that have examined the clinical effectiveness of this teleorthodontic modality with treatment supervised by general practitioners versus orthodontic specialists.

The aim of this study was threefold:

- to objectively assess the clinical effectiveness of teleorthodontic treatment with clear aligners on maxillary and mandibular incisor alignment utilizing the SmileDirectClub ${ }^{\oplus}$ teleorthodontic platform.

- to objectively measure differences in clinical effectiveness between treatment supervised by general practitioners versus orthodontic specialists.

- to subjectively consider patient satisfaction after the teleorthodontic treatment with clear aligners and the relationship between satisfaction and whom the treatment was provided by.

\section{Materials and methods}

New England Independent Review Board (NEIRB, Needham, MA) determined that this research activity (WO-6634) was exempt from IRB approval under the category of research involving the collection or study of existing data, documents, records, pathological specimens, or diagnostic specimens, if the investigator records the information in such a manner that subjects cannot be identified, directly or through identifiers linked to the subjects. A sample of 200 patients that had been treated with the SmileDirectClub ${ }^{\circledR}$ (Nashville, TN) teleorthodontic platform from the practices of endorsed local providers (at least 5 years of experience with Invisalign ${ }^{\circledR}$ treatment) who were either general practitioners or orthodontic specialists was available for study. Patients had consented to the use of their de-identified records prior to their treatment by the treating general practitioner or orthodontic specialist. At the end of treatment, each patient was asked whether or not they were satisfied with the treatment rendered in the form of a yes/no question. The preliminary sample of 200 patients was subjected to the following inclusion and exclusion criteria:

\section{Inclusion criteria}

- Male or Female

- Age 18-45

- Orthodontic problems of anterior tooth crowding no greater than 6 $\mathrm{mm}$ and anterior tooth spacing no greater than $6 \mathrm{~mm}$

- Pre and Posttreatment digital photographs and iTero ${ }^{\circledR}$ (San Jose, CA) intraoral digital scans

Exclusion criteria

\section{Missing photographs or intraoral digital scans}

2. Poor quality of patient records (photographs and digital tooth scans)

3. Did not answer the subjective question of "Are you satisfied with treatment $(\mathrm{Y}$ or $\mathrm{N})$ ?"

After application of the inclusion/exclusion criteria, 127 patients were eligible for the study. A power analysis (set at $80 \%, p<0.05$ ) was used to determine the final sample size. It was concluded that a sample of 50 patients would have sufficient power to detect a meaningful difference between groups. After randomization of the 127 patients using Research Randomizer software [16], a final sample of 50 patients was selected.

Pre-treatment intraoral clinical photographs of each patient were visually reviewed in order to assign their maxillary and mandibular arches to a group by type-crowding or spacing. Maxillary or mandibular arches that did not have treatment were not measured. The pre and posttreatment maxillary and mandibular arch stereolithography (STL) files taken from the iTero digital scans were imported into Autodesk ${ }^{\circledR}$ Meshmixer ${ }^{\mathrm{TM}}$ software (San Rafael, CA) for measurement [17]. Figure 2 illustrates a study patient from the crowding group. This example shows point to point millimetric measurement of crowding from the distal of one lower lateral incisor to the distal of the opposite lateral incisor on the pre and posttreatment models. Those arches in the spacing group were measured by the same method. Posttreatment intraoral clinical photographs of each study patient were visually reviewed and compared with the treatment outcome seen on the digital model. Lastly, the subjective measure of patient satisfaction was tabulated for each patient.

\section{Results and discussion}

Table 1 presents the measures of central tendency and variability associated with the continuous measures of interest included within this study. Mean and median values were generally found to be very similar, suggesting normality. Table 2 presents the sample sizes and 


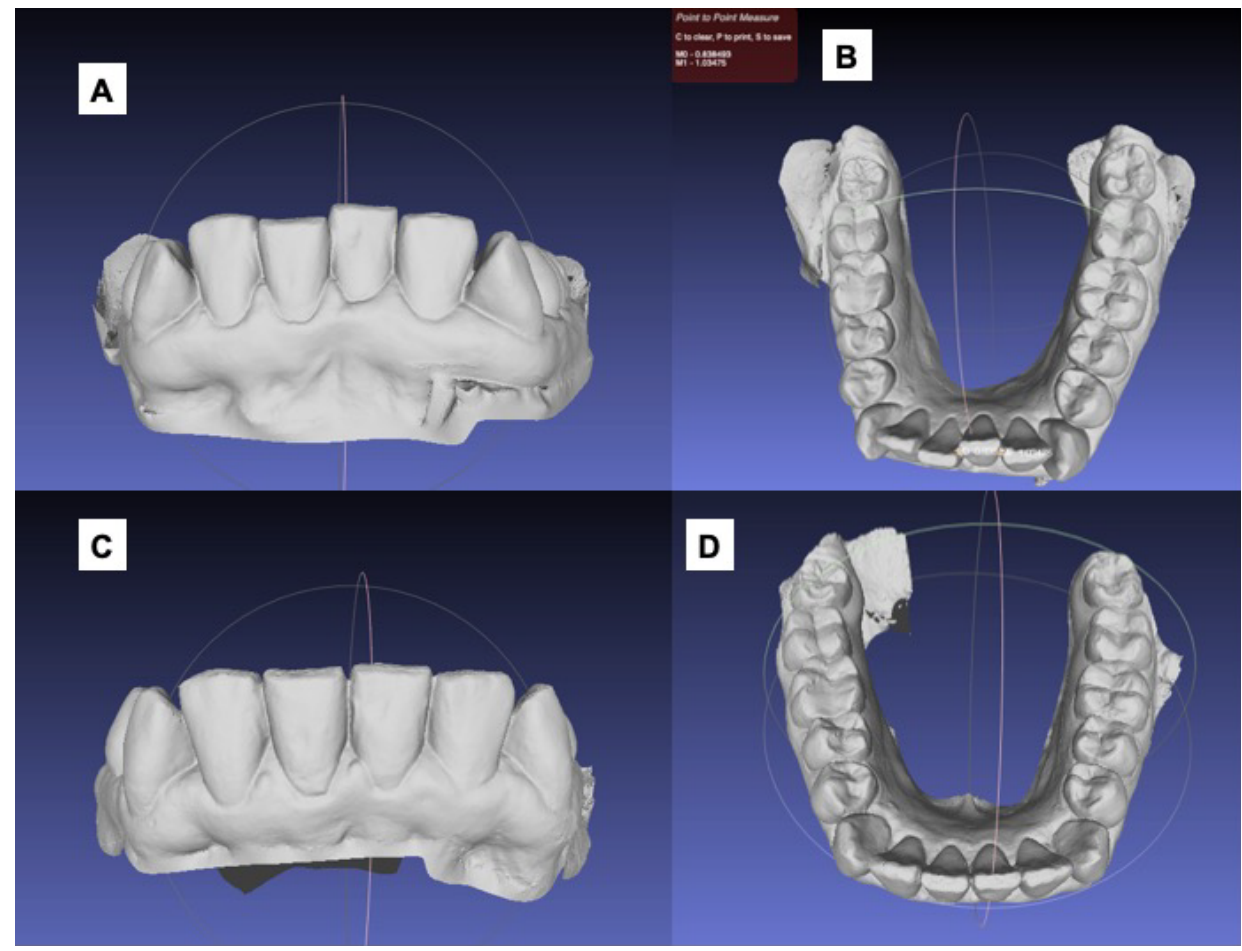

Figure 2. Measurement method. A. Pretreatment digital model created from a stereolithography (STL) file derived from an iTeroTM intraoral scan and imported into the Autodesk ${ }^{\circledR}$ MeshmixerTM software. B. The occlusal view of the pretreatment digital model with point to point measurement across the 4 mandibular incisors. C. Posttreatment digital model. D. The occlusal view of the posttreatment digital model demonstrating resolution of mandibular incisor crowding.

Table 1. Descriptive Statistics: Continuous Measures

\begin{tabular}{|c|c|c|c|c|c|c|}
\hline Measure & Mean & Median & SD & Range & Min & Max \\
\hline Age & 30.04 & 30.00 & 5.86 & 24.00 & 18.00 & 42.00 \\
\hline Maxillary T0 (mm) & 2.73 & 2.28 & 1.66 & 5.00 & 1.00 & 6.00 \\
\hline MaxillaryT1 (mm) & .08 & .00 & .26 & 1.14 & .00 & 1.14 \\
\hline Mandibular T0 (mm) & 2.43 & 1.83 & 1.56 & 5.45 & .55 & 6.00 \\
\hline Mandibular T1 (mm) & .20 & .00 & .41 & 1.68 & .00 & 1.68 \\
\hline Months in Treatment & 5.54 & 5.50 & .86 & 5.00 & 3.00 & 8.00 \\
\hline
\end{tabular}

Table 2. Descriptive Statistics: Categorical Measures

\begin{tabular}{|l|c|c|}
\hline Measure & N & \% \\
\hline Gender & 32 & $64 \%$ \\
\hline Female & 18 & $36 \%$ \\
\hline Male & & \\
\hline Treatment & 30 & $60 \%$ \\
\hline GP & 20 & $40 \%$ \\
\hline Ortho & & \\
\hline Maxillary Type & 24 & $58.54 \%$ \\
\hline Crowding & 17 & $41.46 \%$ \\
\hline Spacing & & \\
\hline Mandibular Type & 35 & $87.50 \%$ \\
\hline Crowding & 5 & $12.50 \%$ \\
\hline Spacing & 4 & $8 \%$ \\
\hline Satisfaction & 46 & $92 \%$ \\
\hline No & & \\
\hline Yes & & \\
\hline
\end{tabular}

frequencies of response with respect to the categorical measures of interest included within this study.

A series of general linear models (GLMs) using SPSS software (IBM, Armonk, NY) were conducted in order to examine treatment effectiveness measured in millimetres and the impact of who the respondent was treated by. Who the respondent was treated by was categorized as either general practitioner or orthodontic specialist, with type categorized as either crowding or spacing. The GLMs incorporated as predictors, only who the respondent was treated by and type. These reduced models were run originally as the sample size of 50 respondents meant that the addition of further predictors such as age or gender would have a substantially greater negative impact on statistical power as compared with studies incorporating a larger sample size, thereby resulting in a greater likelihood of Type II error (the erroneous finding of non-significance).

The first GLM conducted, focused upon maxillary treatment, found only treatment effectiveness to achieve statistical significance in the multivariate tests conducted, $\mathrm{F}(1,37)=105.39, p<0.001$, partial eta-squared $=.74$, observed power $=1.00$. Statistical significance was not indicated with respect to the interaction between treatment and who the respondent was treated by, $\mathrm{F}(1,37)=2.98, p>.05$, partial eta-squared $=.07$, observed power $=.39$, treatment and maxillary type, $\mathrm{F}(1,37)=.39, p>.05$, partial eta-squared $=.01$, observed power $=.09$, or treatment by who the respondent was treated by maxillary type, $\mathrm{F}(1$, $37)=.01, p>.05$, partial eta-squared $<.01$, observed power $=.05$. With respect to the tests of between-subjects effects, statistical significance was not indicated with regard to who the respondent was treated by, $\mathrm{F}(1,37)=3.10, p>.05$, partial eta-squared $=.08$, observed power $=$ .40 , maxillary type, $\mathrm{F}(1,37)=.57, p>.05$, partial eta-squared $=.02$, observed power $=.11$, or the interaction between who the respondent was treated by maxillary type, $\mathrm{F}(1,37)=.01, p>.05$, partial eta-squared $<.00$, observed power $=.05$.

The second GLM conducted focused upon mandibular treatment. This analysis also found only treatment effectiveness to achieve statistical significance in the multivariate tests conducted, $F(1,36)$ $=42.38, p<.001$, partial eta-squared $=.54$, observed power $=1.00$. Statistical significance was not indicated with respect to the interaction between treatment and who the respondent was treated by, $\mathrm{F}(1,36)=$ 

specialists

$.78, p>.05$, partial eta-squared $=.02$, observed power $=.14$, treatment and mandibular type, $\mathrm{F}(1,36)=2.24, p>.05$, partial eta-squared $=.06$, observed power $=.31$, or treatment by who the respondent was treated by mandibular type, $\mathrm{F}(1,36)=1.95, p>.05$, partial eta-squared $=.05$, observed power $=.28$. With respect to the tests of between-subjects effects, statistical significance was not indicated with regard to who the respondent was treated by, $\mathrm{F}(1,36)=.63, p>.05$, partial eta-squared $=.02$, observed power $=.12$, mandibular type, $\mathrm{F}(1,36)=.54, p>.05$, partial eta-squared $=.02$, observed power $=.11$, or the interaction between who the respondent was treated by mandibular type, $\mathrm{F}(1,36)$ $=1.02, p>.05$, partial eta-squared $=.03$, observed power $=.17$. Fisher's exact test was conducted to determine whether there was a significant association between satisfaction and who the respondent was treated by. No significant association was indicated, $p>.05$.

Today, the goal of all orthodontic treatment is the enhancement of a patient's smile thereby increasing their opportunities for education, employment, and even marriage $[17,18]$. Through the use of information technology and the digital health record, dentists are able to utilize teledentistry to diagnose, treatment plan, render treatment and monitor the treatment progress of patients. Access to in office orthodontic treatment with clear aligners for anterior tooth alignment problems has been cost prohibitive for a large segment of the population. As well, this same population group does not have the luxury to take time away from work or childcare to visit a traditional orthodontic office for treatment.

The teleorthodontic treatment modality examined in this study costs $40 \%$ less for the patient than the cost of similar in office orthodontic treatment. This has significantly increased access to care since its introduction nearly 5 years ago. The results of the study suggest that both general practitioners and orthodontic specialists are equally successful at rendering clinically effective teleorthodontic treatment. From an access to care standpoint, this means that the amount of competent dental professionals who can supervise teleorthodontic treatment is exponentially larger and over the next 5 years those patients in geographic areas that do not have orthodontic offices can receive treatment. Although teleorthodontics is in its infancy, the speed with which technology has been improving would indicate that it is only a matter of time before a greater breadth of orthodontic problems will be able to be treated with this modality.

\section{Conclusion}

Study data suggest that teleorthodontic treatment with clear aligners is clinically effective in the correction of maxillary and mandibular incisor alignment problems (crowding or spacing) less than $6 \mathrm{~mm}$. There appears to be no difference in clinical effectiveness between teleorthodontic treatment with clear aligners supervised by general practitioners versus orthodontic specialists. Patient satisfaction after teleorthodontic treatment with clear aligners seems to be unrelated to who provided the treatment, general practitioner or orthodontic specialist.

\section{Conflict of Interests}

The author declares that there is no conflict of interest regarding the publication of this paper.

\section{Acknowledgements}

The author would like to thank Dr. David Kremelberg, DK Statistical Consulting, Inc. for his help with statistical analysis. This project was entirely sponsored by the American Teledentistry Association and all costs related to IRB approval and statistical consulting were paid for by the American Teledentistry Association. The Author has no conflict of interests.

\section{References}

1. Keim RG, Gottlieb EL, Vogels DS, Vogels PB (2015) 2015 JCO orthodontic practice study: Part 1 trends. J Clin Orthod 49: 625-639. [Crossref]

2. Mehrotra A, Paone S, Martich GD, Albert SM, Shevchik GJ (2013) A comparison of care at e-visits and physician office visits for sinusitis and urinary tract infection. JAMA Intern Med 173: 72-74. [Crossref]

3. Namakian M, Subar P, Glassman P, Quade R, Harrington M (2012) In-Person versus "virtual" dental examination: Congruence between decision-making modalities. J Calif Dent Assoc 40: 587-95. [Crossref]

4. Meurer MI, Caffery LJ, Bradford NK, Smith AC (2015) Accuracy of dental images for the diagnosis of dental caries and enamel defects in children and adolescents: A systematic review. $J$ Telemed Telecare 2: 449-458. [Crossref]

5. Queyroux A, Saricassapian B, Herzog D, Muller K, Herafa I, et al. (2017) Accuracy of teledentistry for diagnosis dental pathology using direct examination as a gold standard: Results of teledent study of older adults living in nursing homes. $J$ Am Med Dir Assoc 18: 528-532. [Crossref]

6. Mandall NA, O'Brien KD, Brady J, Worthington HV, Harvey L (2005) Teledentistry for screening new patient orthodontic referrals. Part 1: A randomized controlled trial. Br Dent J 199: 659-662. [Crossref]

7. Irving M, Stewart R, Spallek H, Blinkhorn A (2018) Using teledentistry in clinical practice, an enabler to improve access to oral health care: a qualitative systematic review. J Telemed Telecare 24: 129-146. [Crossref]

8. Estai M, Kanagasingam Y, Tennant M, Bunt S (2018) A systematic review of the research evidence for the benefits of teledentistry. J Telemed Telecare 24: 147-156. [Crossref]

9. Daniel SJ, Kumar S (2014) Teledentistry: a key component in access to care. J Evid Based Dent Pract 14 Suppl: 201-208. [Crossref]

10. National Plan and Provider Enumeration System (NPPES). Research report. Washington, D.C.: U.S. Department of Health and Human Services Centers for Medicare and Medicaid Services; 2017.

11. Kravitz ND, Burris B, Butler D, Dabney CW (2016) Teledentistry, do-it-yourself orthodontics and remote treatment monitoring. J Clin Orthod 50: 718-726. [Crossref]

12. American Association of Orthodontists Consumer Alert. Retrieved on December 10 2018. Available from: http://www.marketwired.com/press-release/consumer-alertrisks-involved-with-do-it-yourself-teeth-straightening-products-1988020.htm.

13. Papadimitriou A, Mousoulea S, Gkantidis N, Kloukos D (2018) Clinical effectiveness of Invisalign $\AA$ orthodontic treatment: a systematic review. Prog Orthod 19: 37. [Crossref]

14. Vicens J, Russo A (2010) Comparative use of Invisalign by orthodontists and general practitioners. Angle Orthod 80: 425-434. [Crossref]

15. Best AD, Shroff B, Carrico CK, Lindauer SJ (2017) Treatment management between orthodontists and general practitioners performing clear aligner therapy. Angle Orthod 87: 432-439. [Crossref]

16. Urbaniak GC, Plous S. Research Randomizer computer software (Version 4.0) Available from: http://www.randomizer.org

17. Ackerman MB. Enhancement Orthodontics: Theory and Practice. Ames: Blackwell Publishing; 2007.

18. Ackerman M, Burris B. Straighter: The Rules of Orthodontics. Orlando: Ackerman \& Burris Publishing; 2018.

Copyright: (C2019 Ackerman MB. This is an open-access article distributed under the terms of the Creative Commons Attribution License, which permits unrestricted use, distribution, and reproduction in any medium, provided the original author and source are credited. 